New Theory

ISSN: 2149-1402
35 (2021) 103-113

Journal of New Theory

https://dergipark.org.tr/en/pub/jnt

Open Access

\title{
An Application of Soft Multisets to a Decision-Making Problem Concerning Side Effects of COVID-19 Vaccines
}

\author{
Şeyda KAYA PEZÜK ${ }^{1}$ (†) Güzide ŞENEL ${ }^{2}$ (1)
}

\begin{abstract}
Article History
Received: 06 Jun 2021

Accepted: 30 Jun 2021

Published: 30 Jun 2021

Research Article

Abstract - Soft multi-criteria decision-making, a developing area, is among the most prevalent problems handled by researchers. This study aims to introduce a soft decision-making method and apply it to rank the side effects of COVID-19 vaccines. Based on the literature, the present study features the advantages and disadvantages of previously observed multi-criteria decision-making (MCDM) methods are summarized. This paper achieves to utilize multisets simultaneously with the known soft decision-making methods. The primary concern hereof is to offer an insightful everydaylife example. Finally, the authors discuss the need for further research.
\end{abstract}

Keywords - Soft sets, multisets, soft multisets, soft decision-making, MCDM

Mathematics Subject Classification (2020) - 03E75, 54A05

\section{Introduction}

Multi-criteria decision-making (MCDM) methods encompass a diverse set of approaches. These methods can be broadly divided into two categories: discrete MCDM or discrete multi-attribute decision-making (MADM) and continuous multi-objective decision-making (MODM) methods [1,2]. A great many publications have recently been released on the development and application of MCDM methods in various fields. This article aims to document the exponentially growing interest in MCDM methods and techniques and reviews the latest literature on MCDM methods and their applications. The foundations of the modern MCDM were established in the 1950s and 1960s. The 1970s marked a critical decade for many pioneering works. The development of MCDM research built momentum in the 1980s and early 1990s and seems to have continued to grow exponentially up to the present time [3]. [4] has formulated the fundamentals of decision-making with multiple objectives. [5] has reviewed the development of MODM methods and their applications in a relatively short period. Later, [6] has analysed the MADM methods: Simple Additive Weighting (SAW) [7], Technique for Order of Preference by Similarity to Ideal Solution (TOPSIS) [7], Elimination and Choice Expressing Reality (ELECTRE) [8], and LINMAP [9]. [10] has published a detailed study on Analytic Hierarchy Process (AHP). Then, the author has published a study on the further development of Analytic Network Process (ANP) and a book which deals with the problem of the compromise theory. [11] has authored a book that addresses the same theory. [5] has studied MCDM in groups. [8] has summed up the available information on the ELECTRE

\footnotetext{
${ }^{1}$ seydakayapezuk@ hotmail.com (Corresponding Author); ${ }^{2}$ g.senel@amasya.edu.tr

${ }^{1,2}$ Department of Mathematics, Faculty of Arts and Sciences, Amasya University, Amasya, Turkey
} 
group method. [12] has written several seminal research papers. Yet the development of hybrid and modular methods has recently become more critical. They are based on the well-known methods, such as SAW [7], TOPSIS [5], AHP [10], and ELECTRE [8], and their modifications by applying fuzzy number and grey number theory. It is evident from the foregoing theoretical discussion that two articles $[13,14]$ stand out. Two other relevant papers have featured soft multisets [15] and soft multi-criteria decision-making [16].

In the current study, section 2 analyses MCDM methods. Section 3 presents some of the basic notions needed for the following sections. Section 4 proposes a new algorithm by modifying the algorithm provided in [16], and then propounds its other version to allow for a comparison with the proposed method. The last section discusses the need for new methods further research.

\section{Analysis of Multi-Criteria Decision-Making Methods}

This section presents a review of 11 methods in the literature. These methods are 1) MAUT, 2) AHP, 3) FST, 4) CBR, 5) DEA, 6) SMART, 7) GP, 8) ELECTRE, 9) PROMETHEE, 10) SAW, and 11) TOPSIS. It is expected that this detailed review will give a deeper insight into these methods.

2.1. Multi-Attribute Utility Theory (MAUT): The most commonly used MCDM approach in this analysis is MAUT [17-19]. This theory has been summarized by Loken as "a more systematic approach to incorporate risk expectations and uncertainty into decision support approaches with multiple parameters" [20]. MAUT's main benefit is that it takes confusion into account. It potentially has a utility attributed to it, which is not a quality that is accounted for in many MCDM methods.

MAUT has been widely applied to attend to economic, environmental, actuarial, and agricultural issues and water and energy management problems. These issues typically exhibit large quantities of ambiguities and provide ample data to make MAUT a proper decision-making process.

2.2. Analytic Hierarchy Process (AHP): While examining the methods, their relationship with the above or other predefined methods is included as well. The MAUT and AHP approaches are based on various assumptions on value measures, and AHP is developed independently of other decision theories. The use of pair-wise comparisons to evaluate alternatives in terms of several parameters as well as to estimate criteria weights is the main characteristic of the AHP system. AHP's implementation and its position in the studies on MCDM have followed a similar pattern as with MAUT and experienced increased usage in real-world application examples. AHP is used to compare weighting and ranking. AHP is capable of navigating various indicators.

2.3. Fuzzy Set Theory (FST): Modelling and handling uncertainties have become essential issues in solving complex problems. FST was introduced by [21] to overcome the problems caused by uncertainties in a wide variety of fields. An efficient MCDM technique itself has been proved to be fuzzy logic. The use of costbenefit analysis as the primary tool for decision analysis to discuss environmental projects has been tackled by [22]. Fuzzy logic "takes into account the insufficient information and the evolution of available knowledge" [23]. Fuzzy systems can also be challenging to build because of drawbacks. In certain instances, before being used in the real world, they can require multiple simulations. FST has been developed and used in such fields as engineering, economics, medicine, and environmental and social sciences.

2.4. Case-Based Reasoning (CBR): There are two popular ways to distinguish between companies in financial distress and those in healthy financial situations: human preference-oriented forecasting and datadriven forecasting. [24] uses CBR to provide a new framework for forecasting financial distress in businesses one year before the real distress. Employing the Manhattan distance, Euclidean distance, and inductive form, CBR compares three different models and their respective results with a ranking-order case-based model of reasoning (ROCBR). One of CBR's key advantages over most MCDM techniques is that it can improve over time, especially as more instances are added to the database. Through its database of events, it can also respond to environmental changes. Its significant downside is its vulnerability to data inconsistencies. 
2.5. Data Envelopment Analysis (DEA) [25]: DEA is used to develop a model that will help policymakers of any country prioritize their actions. The goal thereof is to improve the relevant highways in the most efficient way possible. This method is able to successfully score the productivity of countries by obtaining 21 separate data. In this method, a mutual comparison is made. The comparison method refers to the grading of the efficiency of the most efficient alternatives. With a rating of 1.0, all the other alternatives are a fraction of 1.0. This offers several advantages. The most essential one is that multiple inputs and outputs can be processed.

2.6. Simple Multi-Attribute Rating Technique (SMART) [26]: SMART counts as one of the most accessible categories of MAUT. Its name derives from its convenient use. This approach requires two assumptions, "preferential independence" and "utility independence". In conjunction with the real numbers, this approach transforms significance weights into real numbers. In addition to those described in MAUT, the key benefits of SMART relative to the MAUT system are that it is easy to use and genuinely facilitates any form of weight assignment technique.

2.7. Goal Programming (GP) [13]: GP is a realistic type of programming that provides an unlimited number of solutions to choose from. All of its strengths are that it can address large-scale concerns. Its most notable value, according to some methods, is the potential to generate limitless alternatives. A significant downside to this strategy is that the coefficients are not weighted. To accurately weight the coefficients, many implementations find it appropriate to use other approaches, such as AHP. This condition is not, however, present in this process. It eliminates one of its drawbacks by doing this while choosing infinite options, which can cause option inconsistencies. This follows a general trend that in applications that avoid many of their drawbacks, MCDM approaches are most frequently used - i.e., that coefficient weight does not care.

2.8. ELECTRE [8]: The areas in which ELECTRE is used are issues with electricity, economy, environment, water management, and transport. It considers ambiguity as other approaches do. ELECTRE is a form of transformation of several iterations dependent on compatibility analysis. Its greatest value is that it takes into account complexity and uncertainty. Its downside is that it may be difficult to describe the mechanism and its consequences concerning its terms and poor comprehensibility.

2.9. PROMETHEE [27]: PROMETHEE is similar to the aforesaid ELECTRE method in that it has multiple iterations and is also a transformation method. Its value is that it is convenient to use. The presumption that the parameters are proportional does not require it. The drawbacks are that it provides no explicit weight distribution method and allows weights to be allocated. Still, it fails to offer a consistent method for assigning these values.

2.10. SAW [7]: "SAW is a value function established based on a simple addition of scores representing the goal achievement under each criterion, multiplied by the particular weights" [7]. Its ability to compensate between criteria is among the reasons for its selection in usage. For policymakers, it is intuitive as well. It is easy to use thanks to its ability to render calculations without basic and complicated computer programs.

2.11. TOPSIS [5]: Its main benefits are that it has a clear method and it is accessible and programmable. Regardless of the number of attributes, the number of phases remain the same. It can be inferred from most of the uses in the literature that TOPSIS confirms the responses proposed by other methods of MCDM. The value of its flexibility and the potential to retain the same number of steps regardless of the challenge scale helps it be easily used as a decision-making mechanism for evaluating or retaining other approaches in its own right.

\section{Preliminaries}

This section provides some of the basic definitions to be needed for the following sections.

Definition 3.1. Soft sets [28, as cited in 29] Let $U$ be an initial universe, $P(U)$ be the power set of $U, E$ be the set of parameters, and $A \subseteq E$. Then, a soft set $F_{A}$ over $U$ is defined as $F_{A}:=\left\{\left(x, f_{A}(x)\right): x \in E\right\}$ where $f_{A}: E \rightarrow P(U)$ is a mapping and $x \notin A$ for $f_{A}(x)=\emptyset$. 
Definition 3.2. Multisets [30] Let $U$ be universal set, $\mathbb{N}$ be a set of unsigned integer numbers, and $X \subseteq$ $U$. Then, a multiset $M_{X}$ over $U$ is defined as

$$
M_{X}:=\left\{\frac{f_{X}(u)}{u}: u \in U\right\}
$$

where $f_{X}: U \rightarrow \mathbb{N}$ be a mapping such that $u \notin X$ for $f_{X}(u)=0$ Here, $\frac{f_{X}(u)}{u}$ means that $u$ occurring $f_{X}(u)$ times. Moreover, if $f_{X}(u)=0$, then $\frac{f_{X}(u)}{u}$ is not shown in the multiset. Here, if $X=U$, MSs can be denoted by $\mathrm{M}$ or $\mathrm{M}_{1}, \mathrm{M}_{2}, \ldots$

Definition 3.3. [30] Let $M_{X}, M_{Y}$ be two multisets over $U$. If, for all $u \in U, f_{X}(u) \leq f_{Y}(u)$, then $M_{X}$ is called multi-subset of $M_{Y}$ and is denoted by $M_{X} \widetilde{\subseteq} M_{Y}$.

Example 3.4. Let $U=\left\{u_{1}, u_{2}, u_{3}\right\}, X=\left\{u_{1}, u_{3}\right\}$, and $f_{X}: U \rightarrow \mathbb{N}$ is a mapping defined by $f_{X}\left(u_{1}\right)=25$, $f_{X}\left(u_{2}\right)=33$, and $f_{X}\left(u_{3}\right)=40$. Then, the multiset $M_{X}=\left\{\frac{25}{u_{1}}, \frac{0}{u_{2}}, \frac{40}{u_{3}}\right\}$ briefly $M_{X}=\left\{\frac{25}{u_{1}}, \frac{40}{u_{3}}\right\}$. Similarly, let $Y=U$ and $M_{Y}=\left\{\frac{32}{u_{1}}, \frac{10}{u_{2}}, \frac{50}{u_{3}}\right\}$. Then, $M_{X} \widetilde{\subseteq} M_{Y}$ since

$$
\begin{gathered}
f_{X}\left(u_{1}\right)=25 \leq f_{Y}\left(u_{1}\right)=32 \\
f_{X}\left(u_{2}\right)=0 \leq f_{Y}\left(u_{2}\right)=10 \\
f_{X}\left(u_{3}\right)=40 \leq f_{Y}\left(u_{3}\right)=50
\end{gathered}
$$

Definition 3.5. [30] Let $M_{U}$ be a multiset over $U$ and $n \in \mathbb{N}$. If, for all $u \in U, f_{U}(u)=n$, then $M_{U}$ is called n-multi-set over $U$ and is denoted by $M^{n}$. If, for all $X \subseteq U, \max _{u \in X} f_{X}(u)=n$, then $M^{n}$ is referred to as n-universal multiset over $U$. Here, $M^{0}$ is called empty multiset over $U$. It can be observed that $M_{\varnothing}$ is empty multiset over $U$.

Definition 3.6. Soft multisets (SMSs) [31] Let $M_{V}$ be a multiset, $M\left(M_{V}\right)$ be the set of all the multiset of $U$, $E$ be parameters set, and $A \subseteq E$. Then, a soft multiset (SMS) $\Omega_{A}$ over $Z_{K}$ is defined as

$$
\Omega_{A}:=\left\{\left(x, \Omega_{A}(x)\right): x \in E\right\}
$$

where $\Omega_{A}: E \rightarrow M(U)$ is a mapping such that $\Omega_{A}(x)=M^{0}$ if $x \notin A$. Here, if $A=E$, SMSs can be denoted by $\Omega$ or $\Omega_{1}, \Omega_{2}, \ldots$

Definition 3.7. Fuzzy set [21] Let $U$ be an initial universe, [0,1] be unit closed interval, and $\mu: U \rightarrow[0,1]$ be a mapping, Then, a fuzzy set $\mu$ over $U$ is defined as

$$
\mu:=\{(x, \mu(x)): x \in U\} \text { or briefly } \mu:=\left\{{ }^{\mu(x)} x: x \in U\right\}
$$

Definition 3.8. Fuzzy soft set [32, as cited 33] Let $U$ be an initial universe, $F(U)$ be the set of all the fuzzy sets over $U, E$ be parameters set, and $A \subseteq E$. Then, a fuzzy soft set $\Gamma_{A}$ over $U$ is defined as

$$
\Gamma_{A}:=\left\{\left(x, \Gamma_{A}(x)\right): x \in E\right\}
$$

where $\Gamma_{A}: E \rightarrow F(U)$ is a mapping such that $\Gamma_{A}(x)=\mathbf{0}$ if $x \notin A$. Here, $\mathbf{0}$ denotes the empty fuzzy set. Moreover, if $A=E$, fuzzy soft sets can be denoted by $\Gamma$ or $\Gamma_{1}, \Gamma_{2}, \ldots$

Definition 3.9. [34, as cited in 35] Let $U$ be an initial universe, $E$ be parameters set, $A \subseteq E$, and $\Gamma_{A}$ be a fuzzy soft set over $U$. Then, $\left[a_{i j}\right]$ is called fuzzy soft matrix of $\Gamma_{A}$ and is defined by 


$$
\left[a_{i j}\right]=\left[\begin{array}{llllll}
a_{11} & a_{12} & a_{13} & \ldots & a_{1 n} & \ldots \\
a_{21} & a_{22} & a_{23} & \ldots & a_{2 n} & \ldots \\
\vdots & \vdots & \vdots & \ddots & \vdots & \vdots \\
a_{m 1} & a_{m 2} & a_{m 3} & \ldots & a_{m n} & \ldots \\
\vdots & \vdots & \vdots & \ddots & \vdots & \ddots
\end{array}\right]
$$

such that for $i, j \in\{0,1,2, \cdots\}, a_{i j}:=\Gamma_{\mathrm{A}}\left(x_{j}\right)\left(u_{i}\right)$ where $\Gamma_{\mathrm{A}}\left(x_{j}\right)\left(u_{i}\right)$ refers to the membership degree of $u_{i}$ in the fuzzy set $\Gamma_{\mathrm{A}}\left(x_{j}\right)$. Here, if $|U|=m$ and $|E|=n$, then $\left[a_{i j}\right]$ has order $m \times n$.

Definition 3.10. Let $\left[s_{i 1}\right]$ be a real matrix has order $m \times 1$. Then, normalisation $\left[\hat{s}_{i 1}\right]$ of $\left[s_{i 1}\right]$ is defined by

$$
\hat{s}_{i 1}:=\left\{\begin{array}{cl}
\frac{s_{i 1}-\min _{k} s_{k 1}}{\max _{k} s_{k 1}-\min _{k} s_{k 1}}, & \max _{k} s_{k 1} \neq \min _{k} s_{k 1} \\
1, & \max _{k} s_{k 1}=\min _{k} s_{k 1}
\end{array}\right.
$$

\section{An Application of Soft Multisets to a Decision-Making Problem Concerning Side Effects of COVID-19 Vaccines}

Firstly, this section presents the data on the post-treatment side effects of the COVID-19 vaccine provided in [36-39] and obtained by the feedback received from 791, 530, 80, and 814 people located in Manisa/Turkey, the United States, Konya/Turkey, and the Czech Republic, respectively. The COVID-19 pandemic, identified in 59 suspect cases (In Hubei/Wuhan, China), has spread to affect the whole world [40-41]. Authorities have launched vaccination campaigns to prevent its spread. In this sense, several types of vaccines have been developed (for more about the properties of the COVID-19 vaccines, see [41-42]).

\begin{tabular}{|c|c|c|c|c|c|}
\hline & Symptoms / Sources & $n^{*}=791[36]$ & $\mathbf{n}=\mathbf{5 3 0}[\mathbf{3 7}]$ & $\mathrm{n}=\mathbf{8 0}[38]$ & $\mathrm{n}=\mathbf{8 1 4}[39]$ \\
\hline$s_{1}$ & Headache & 11.9 & 13 & 13.8 & 45.6 \\
\hline $\boldsymbol{s}_{2}$ & Muscle/joint pain & 9.5 & 11.6 & 46.3 & 64.9 \\
\hline$s_{3}$ & Sore Throat & 3.7 & 8.5 & 23.8 & - \\
\hline$s_{4}$ & Chills/Fever & 3.2 & 2.8 & 37.5 & 55.6 \\
\hline$s_{5}$ & Diarrhoea/Nausea/Vomiting & 3.4 & 5.7 & 5 & 13 \\
\hline$s_{6}$ & Loss/change in taste or smell & 1.2 & 1.6 & 6.3 & 10 \\
\hline$s_{7}$ & Cough & 1.6 & 9.9 & 61.3 & - \\
\hline$s_{8}$ & Hypertension & 0.9 & - & 26.2 & - \\
\hline$S_{9}$ & Shortness of breath & 0.4 & 4.1 & 20 & - \\
\hline$s_{10}$ & Injection site pain & 18 & - & - & 89.8 \\
\hline$s_{11}$ & Injection site swelling & 1.3 & - & - & 25.6 \\
\hline$s_{12}$ & Injection site itching/redness & 1.4 & - & - & 23 \\
\hline$s_{13}$ & Lymphadenopathy & 0.4 & - & - & 16.2 \\
\hline$s_{14}$ & Fatigue & - & 17.9 & 50 & 62.2 \\
\hline
\end{tabular}

Table 1. By-Symptom Distribution of the frequency of side effects (\%) of COVID-19 vaccine

Secondly, this section presents two soft decision-making (SDM) methods provided in [43,44]. Since these SDM methods have been configured to operate in the fuzzy parameterized fuzzy soft matrices space, they are reduced to the fuzzy soft matrices space. 


\section{Algorithm Steps of sMBR01 [43]}

Step 1: Construct a fuzzy soft matrix $\left[a_{i j}\right]$ has order $m \times n$

Step 2: Obtain $\left[s_{i 1}\right]$ defined by

$$
s_{i 1}:=\sum_{k=1}^{m} \sum_{j=1}^{n} \operatorname{sgn}\left(a_{i j}-a_{k j}\right), \quad i \in\{1,2, \ldots, m\}
$$

Step 3: Obtain the decision set $\left\{\hat{s}_{k 1} u_{k} \mid u_{k} \in U\right\}$

\section{Algorithm Steps of CCE10 [44]}

Step 1: Construct a fuzzy soft matrix $\left[a_{i j}\right]$ has order $m \times n$

Step 2: Obtain the score matrix $\left[s_{i 1}\right]$ defined by

$$
s_{i 1}:=\frac{1}{\mathrm{n}} \sum_{j=1}^{n} a_{i j}, \quad i \in\{1,2, \ldots, m\}
$$

Step 3: Obtain the decision set $\left\{\hat{s}_{k 1} u_{k} \mid u_{k} \in U\right\}$

Thirdly, this section proposes a new algorithm, denoted by KPS21, by modifying the algorithm provided in [16]. Then, it propounds its other version, i.e., KPS21/2, to allow for a comparison with KPS21. These methods achieve to utilize multisets simultaneously with the known soft decision-making methods.

\section{Algorithm Steps of KPS21}

Step 1: Input a parameter set $E, A \subseteq E$, a universal set $U$, and $X \subseteq U$

Step 2: Construct a multiset $M_{X}$ over $U$

Step 3: Construct an SMS $\Omega_{\mathrm{A}}$ over $U$

Step 4: Compute the fuzzy soft set $\Gamma_{A}=\left\{\left(x, \Gamma_{A}(x)\right): x \in E\right\}$ defined by

$$
\Gamma_{A}(x)=\left\{\frac{\Omega_{A}(x)(u) / \sum_{v} \Omega_{A}(x)(v)}{u}: x \in E\right\}
$$

Step 5: Obtain the fuzzy soft matrices $\left[a_{i j}\right]$

Step 6: Apply sMBR01 to the $\left[a_{i j}\right]$

\section{Algorithm Steps of KPS21/2}

Step 1: Input a parameter set $E, A \subseteq E$, a universal set $U$, and $X \subseteq U$

Step 2: Construct a multiset $M_{X}$ over $U$

Step 3: Construct an SMS $\Omega_{\mathrm{A}}$ over $U$

Step 4: Compute the fuzzy soft set $\Gamma_{A}=\left\{\left(x, \Gamma_{A}(x)\right): x \in E\right\}$ defined by

$$
\Gamma_{A}(x)=\left\{\frac{\Omega_{A}(x)(u) / \sum_{v} \Omega_{A}(x)(v)}{u}: x \in E\right\}
$$

Step 5: Obtain the fuzzy soft matrices $\left[a_{i j}\right]$

Step 6: Apply CEC11 to the $\left[a_{i j}\right]$

Fourthly, this section applies KPS21 and KPS21/2 to the side-effect data provided in Table 1.

Step 1: $E=\left\{x_{1}, x_{2}, x_{3}, x_{4}\right\}, A=E, U=\left\{u_{1}, u_{2}, \ldots, u_{14}\right\}$, and $X=U$ such that

$u_{i}=s_{i}$ for all $i \in\{1,2, \ldots, 14\}$ 
$x_{1}=$ Data located in Manisa/Turkey

$x_{2}=$ Data located in the United States

$x_{3}=$ Data located in Konya/Turkey

$x_{4}=$ Data located in the Czech Republic

Step 2: The multisets $M_{1}, M_{2}, M_{3}$ and $M_{4}$ over $U$, which show the distribution of side effects and whose values are obtained by rounding the values provided in Table 1 to the nearest integer number, are as follows:

$$
\begin{gathered}
M_{1}=\left\langle\frac{12}{u_{1}}, \frac{10}{u_{2}}, \frac{4}{u_{3}}, \frac{3}{u_{4}}, \frac{3}{u_{5}}, \frac{1}{u_{6}}, \frac{2}{u_{7}}, \frac{1}{u_{8}}, \frac{18}{u_{10}}, \frac{1}{u_{11}}, \frac{1}{u_{12}}\right\rangle \\
M_{2}=\left\langle\frac{13}{u_{1}}, \frac{12}{u_{2}}, \frac{9}{u_{3}}, \frac{3}{u_{4}}, \frac{6}{u_{5}}, \frac{2}{u_{6}}, \frac{10}{u_{7}}, \frac{4}{u_{9}}, \frac{18}{u_{14}}\right\rangle \\
M_{3}=\left\langle\frac{14}{u_{1}}, \frac{46}{u_{2}}, \frac{24}{u_{3}}, \frac{38}{u_{4}}, \frac{5}{u_{5}}, \frac{6}{u_{6}}, \frac{61}{u_{7}}, \frac{26}{u_{8}}, \frac{20}{u_{9}}, \frac{50}{u_{14}}\right\rangle \\
M_{4}=\left\langle\frac{46}{u_{1}}, \frac{65}{u_{2}}, \frac{56}{u_{4}}, \frac{13}{u_{5}}, \frac{10}{u_{6}}, \frac{90}{u_{10}}, \frac{26}{u_{11}}, \frac{23}{u_{12}}, \frac{16}{u_{13}}, \frac{62}{u_{14}}\right\rangle
\end{gathered}
$$

Step 3: Thus, an SMS $\Omega$ over $U$ is as follows:

$$
\Omega=\left\{\left(x_{1}, M_{1}\right),\left(x_{2}, M_{2}\right),\left(x_{3}, M_{3}\right),\left(x_{3}, M_{4}\right)\right\}
$$

Step 4: Therefore, the fuzzy soft set $\Gamma$

$$
\Gamma=\left\{\begin{array}{c}
\left(x_{1},\left\{{ }^{0.21} u_{1},{ }^{0.18} u_{2},{ }^{0.07} u_{3},{ }^{0.05} u_{4},{ }^{0.05} u_{5},{ }^{0.02} u_{6},{ }^{0.04} u_{7},{ }^{0.02} u_{8},{ }^{0.32} u_{10},{ }^{0.02} u_{11},{ }^{0.02} u_{12}\right\}\right), \\
\left.\left(x_{2},{ }^{0.17} u_{1},{ }^{0.16} u_{2},{ }^{0.12} u_{3},{ }^{0.04} u_{4},{ }^{0.08} u_{5},{ }^{0.03} u_{6},{ }^{0.13} u_{7},{ }^{0.05} u_{9},{ }^{0.23} u_{14}\right\}\right), \\
\left(x_{3},\left\{{ }^{0.05} u_{1},{ }^{0.16} u_{2},{ }^{0.08} u_{3},{ }^{0.13} u_{4},{ }^{0.02} u_{5},{ }^{0.02} u_{6},{ }^{0.21} u_{7},{ }^{0.09} u_{8},{ }^{0.07} u_{9},{ }^{0.17} u_{14}\right\}\right), \\
\left(x_{4},\left\{{ }^{0.11} u_{1},{ }^{0.16} u_{2},{ }^{0.14} u_{3},{ }^{0.03} u_{4},{ }^{0.02} u_{5},{ }^{0.22} u_{6},{ }^{0.06} u_{7},{ }^{0.06} u_{8},{ }^{0.04} u_{9},{ }^{0.15} u_{14}\right\}\right),
\end{array}\right\}
$$

Step 5: The fuzzy soft matrix of $\Gamma$ is as follows:

$$
\left[a_{i j}\right]=\left[\begin{array}{cccc}
0.21 & 0.17 & 0.05 & 0.11 \\
0.18 & 0.16 & 0.16 & 0.16 \\
0.07 & 0.12 & 0.08 & 0 \\
0.05 & 0.04 & 0.13 & 0.14 \\
0.05 & 0.08 & 0.02 & 0.03 \\
0.02 & 0.03 & 0.02 & 0.02 \\
0.04 & 0.13 & 0.21 & 0 \\
0.02 & 0 & 0.09 & 0 \\
0 & 0.05 & 0.07 & 0 \\
0.32 & 0 & 0 & 0.22 \\
0.02 & 0 & 0 & 0.06 \\
0.02 & 0 & 0 & 0.06 \\
0 & 0 & 0 & 0.04 \\
0 & 0.23 & 0.17 & 0.15
\end{array}\right]
$$

Step 6: The decision set and the rank of the alternatives obtained by sMBR01 are as follows:

$$
\left\{{ }^{0.83} u_{1},{ }^{1} u_{2},{ }^{0.52} u_{3},{ }^{0.7} u_{4},{ }^{0.45} u_{5},{ }^{0.22} u_{6},{ }^{0.61} u_{7},{ }^{0.19} u_{8},{ }^{0.03} u_{9},{ }^{0.7} u_{10},{ }^{0.14} u_{11},{ }^{0.14} u_{12},{ }^{0} u_{13},{ }^{0.77} u_{14}\right\}
$$

and 


$$
u_{13} \prec u_{9} \prec u_{11} \approx u_{12} \prec u_{8} \prec u_{6} \prec u_{5} \prec u_{3} \prec u_{7} \prec u_{4} \approx u_{10} \prec u_{14} \prec u_{1} \prec u_{2}
$$

Similarly, the decision set and the rank of the alternatives obtained by CEC11 is as follows:

$$
\left\{{ }^{0.82} u_{1},{ }^{1} u_{2},{ }^{0.41} u_{3},{ }^{0.54} u_{4},{ }^{0.27} u_{5},{ }^{0.14} u_{6},{ }^{0.58} u_{7},{ }^{0.17} u_{8},{ }^{0.11} u_{9},{ }^{0.89} u_{10},{ }^{0.12} u_{11},{ }^{0.12} u_{12},{ }^{0.06} u_{13},{ }^{0.83} u_{14}\right\}
$$

and

$$
u_{13} \prec u_{9} \prec u_{11} \approx u_{12} \prec u_{8}<u_{6}<u_{5} \prec u_{3} \prec u_{4} \prec u_{7} \prec u_{1} \prec u_{14} \prec u_{10} \prec u_{2}
$$

Both of the results manifest that the appearance rates of the side effects $u_{13}, u_{9}, u_{11}, u_{12}, u_{8}, u_{6}$, and $u_{5}$ account for less than $50 \%$, and the methods produce the same ranking orders for these alternatives. Moreover, the appearance rates of the side effects $u_{3}, u_{7}, u_{4}, u_{10}, u_{14}, u_{1}$, and $u_{2}$ are greater than $50 \%$, and the methods produce the same ranking orders for $u_{3}$ and $u_{2}$, while those of the others are different. sMBR01 and CEC11 methods are reliable since they pass all the tests provided in [45]. KPS21 and KPS21/2 methods are also reliable as they are based on the aforesaid methods, respectively. However, the uncertainty inherent in the problem causes some of the produced ranking orders to be different.

\section{Conclusion}

In this study, an example of an algorithm used in alternative decision-making processes was introduced to provide a working example of the MCDM method for selecting alternatives used in everyday life and the decisions that can be reached with the help of the concept of soft sets emerging on the concept of uncertainties. It is believed that the algorithms proposed in this study can be used in different disciplines and will offer guidance for future studies. Moreover, to improve the proposed method, it is worth studying the current soft decision-making methods [46-52].

\section{Conflict of Interest}

The authors declare no conflict of interest.

\section{References}

[1] N. Chauhan, P. Mohapatra, K. Pandey, Improving Energy Productivity in Paddy Production Through Benchmarking-An Application of Data Envelopment Analysis, Energy Conversion and Management 47(9-10) (2006) 1063-1085.

[2] E. K. Zavadskas, Z. Turskis, S. Kildiene, State of Art Surveys of Overviews on MCDM/MADM Methods, Technological and Economic Development of Economy 20(1) (2014) 165-179.

[3] M. M. Köksalan, J. Wallenius, S. Zionts, Multiple Criteria Decision Making: From Early History to the 21 st Century, World Scientific (2011) https://doi.org/10.1142/8042

[4] R. Keeney, The Art of Assessing Multiattribute Utility Functions, Organizational Behavior and Human Performance 19(2) (1977) 267-310.

[5] C. L. Hwang, K. Yoon, Methods for Multiple Attribute Decision Making, In Multiple Attribute Decision Making (1981) Springer, Berlin, Heidelberg, pp. 58-191.

[6] G. H. Tzeng, C. H. Chiang, C. W. Li, Evaluating Intertwined Effects in E-Learning Programs: A Novel Hybrid MCDM Model Based on Factor Analysis and DEMATEL, Expert Systems with Applications 32(4) (2007) 1028-1044.

[7] X. S. Qin, G. H. Huang, A. Chakma, X. H. Nie, Q. G. Lin, A MCDM-Based Expert System for ClimateChange Impact Assessment and Adaptation Planning-A Case Study for The Georgia Basin, Canada, Expert Systems with Applications 34(3) (2008) 2164-2179. 
[8] B. Roy, ELECTRE III: A Ranking Algorithm Based on A Fuzzy Representation of Preferences in the Presence of Multiple Criteria (In French) 20(1) (1978) 3-4.

[9] V. Srinivasan, A. D. Shocker, Linear Programming Techniques for Multidimensional Analysis of Preferences, Psychometrika 38(3) (1973) 337-369.

[10] T. L. Saaty, The Analytic Hierarchy Process (AHP), The Journal of the Operational Research Society 41(11) (1980) 1073-1076.

[11] M. Zeleny, J. L. Cochrane, Multiple Criteria Decision Making, University of South Carolina Press (1973) Columbia.

[12] V. Belton, T. Stewart, Multiple Criteria Decision Analysis: An Integrated Approach, Springer Science \& Business Media (2002) 372.

[13] M. Velasquez, P. T. Hester, An Analysis of Multi-Criteria Decision-Making Methods, International Journal of Operations Research 10(2) (2013) 56-66.

[14] C. Kahraman, S. C. Onar, B. Oztaysi, Fuzzy Multi-Criteria Decision-Making: A Literature Review, International Journal of Computational Intelligence Systems 8(4) (2015) 637-666.

[15] D. Tokat, İ. Osmanoğlu, Soft Multi Set and Soft Multi Topology, Journal of Nevsehir University Institue of Science 2 (2011) 109-118.

[16] M. Riaz, N. Çağman, N. Wali, A. Mushtaq, Certain Properties of Soft Multi-Set Topology with Applications in Multi-Criteria Decision Making, Applications in Management and Engineering 3(2) (2020) 70-96.

[17] P. C. Fishburn, Conjoint Measurement in Utility Theory with Incomplete Product Sets, Journal of Mathematical Psychology 4(1) (1967) 104-119.

[18] P. C. Fishburn, R. L. Keeney, Seven Independence Concepts and Continuous Multiattribute Utility Functions, Journal of Mathematical Psychology 11(3) (1974) 294-327.

[19] R. L. Keeney, The Art of Assessing Multiattribute Utility Functions, Organizational Behavior and Human Performance 19(2) (1977) 267-310.

[20] E. Loken, Use of Multi-Criteria Decision Analysis Methods for Energy Planning Problems, Renewable and Sustainable Energy Reviews 11(7) (2007) 1584-1595.

[21] L. Zadeh, Fuzzy Sets, Information and Control 8(3) (1965) 338-353.

[22] I. M. Khadam, J. J. Kaluarachchi, Multi-Criteria Decision Analysis with Probabilistic Risk Assessment for the Management of Contaminated Ground Water, Environmental Impact Assessment Review 23(6) (2003) 683-721.

[23] J. F. Balmat, F. Lafont, R. Maifret, N. Pessel, A Decision-Making System to Maritime Risk Assessment, Ocean Engineering 38(1) (2011) 171-176.

[24] H. Li, J. Sun, Ranking-Order Case-Based Reasoning for Financial Distress Prediction, KnowledgeBased Systems 21(8) (2008) 868-878.

[25] E. Thanassoulis, M. Kortelainen, R. Allen, Improving Envelopment in Data Envelopment Analysis Under Variable Returns to Scale, European Journal of Operational Research 218(1) (2012) 175-185.

[26] Y. Chen, G. Okudan, D. Riley, Decision Support for Construction Method Selection in Concrete Buildings: Prefabrication Adoption and Optimization, Automation in Construction 19(6) (2010) 665675. 
[27] J. P. Brans, P. Vincke, B. Mareschal, How to Select and How to Rank Projects: The PROMETHEE Method, European Journal of Operational Research 24(2) (1986) 228-238.

[28] D. Molodtsov, Soft Set Theory-First Results, Computers \& Mathematics with Applications 37(4-5) (1999) 19-31.

[29] N. Çağman, S. Enginoğlu, Soft Sets Theory and Uni-Int Decision-Making, Computers \& Mathematics with Applications 207 (2010) 847-855.

[30] S. Apostolos, Mathematics of Multisets. Multiset Processing (2001) LNCS, 2235, 347-358.

[31] K.V. Babitha, S.J. John, On Soft Multiset, Annals of Fuzzy Mathematics and Informatics 5(1) (2013) 3544

[32] P. K. Maji, A. R. Roy, R. Biswas, Fuzzy Soft Sets, Journal of Fuzzy Mathematics 9(3) (2001) 589-602.

[33] N. Çağman, S. Enginoğlu, F. Çıtak, Fuzzy Soft Set Theory and Its Applications, Iranian Journal of Fuzzy Systems 8(3) (2017) 137-147.

[34] N. Çağman, S. Enginoğlu, Fuzzy Soft Matrix Theory and Its Application in Decision-Making, Iranian Journal of Fuzzy Systems 9(1) (2012) 109-119.

[35] S. Enginoğlu, M. Ay, N. Çağman, V. Tolun, Classification of the Monolithic Columns Produced in Troad and Mysia Region Ancient Granite Quarries in Northwestern Anatolia via Soft Decision-Making, Bilge International Journal of Science and Technology Research 3(Special Issue) (2019) 21-34.

[36] Ş. Şenol, E. Eser, S. Akçalı, B. C. Özyurt, P. E. Dündar, T. Ecemiş, ..., Interim Results of the "CoronaVac Vaccine Protection Study" (In Turkish),

https://www.mcbu.edu.tr/Haber/MCBUTipFakultesiHastanesiSaglikCalisanlarininYuruttuguCoronova VacAsiKoruyuculuguCalismasiAraSonuclariniYYayimladi_19_35_35 Access Date: 09.04.2021

[37] K. Michaud, K. Wipfler, Y. Shaw, T. A. Simon, A. Cornish, B. R. England, ..., Experiences of Patients with Rheumatic Diseases in the United States During Early Days of the COVID-19 Pandemic, American College of Rheumatology 2(6) (2020) 335-343.

[38] E. B. Batur, M. K. Korez, I. A. Gezer, F. Levendoğlu, O. Ural, Musculoskeletal symptoms and relationship with laboratory findings in patients with COVID-19, International Journal of Clinical Practice 75(6) (2021) 1-7. https://doi.org/10.1111/ijcp.14135

[39] A. Riad, A. Pokorná, S. Attia, J. Klugarová, M. Košcík, M. Klugar, Prevalence of COVID-19 Vaccine Side Effects among Healthcare Workers in the Czech Republic, Journal of Clinical Medicine 10 (2021) 1-18. https://doi.org/10.3390/jcm10071428

[40] Y. Demirbilek, G. Pehlivantürk, Z. Ö. Özgüler, E. A. Meşe, COVID-19 Outbreak Control, Example of Ministry of Health of Turkey, Turkish Journal of Medical Sciences 50(SI-1) (2014) 489-494.

[41] S. Çağlar, What Does It Really Mean When the COVID-19 Vaccine is 95\% Effective? (In Turkish) https://www.matematiksel.org/COVID-19-asisi-95-etkili-demek-gercekte-ne-anlama-geliyor/ Access Date: 09.04.2021.

[42] B. Meral, How Do Vaccines Work? How Does it Strengthen the Immune System? (In Turkish) https://www.matematiksel.org/asilar-nasil-calisir-bagisiklik-sistemini-nasil-guclendirir/ Access Date: 09.04.2021

[43] S, Enginoğlu, S, Memiş, Comment on Fuzzy Soft Sets [The Journal of Fuzzy Mathematics, 9(3), 2001, 589 602], International Journal of Latest Engineering Research and Applications 3(9) (2018) 1-9.

[44] S. Enginoğlu, S. Memiş, A Configuration of Some Soft Decision-Making Algorithms via fpfs-matrices, Cumhuriyet Science Journal 39(4) (2018) 871-881. 
[45] S. Enginoğlu, T. Aydın, S. Memiş, B. Arslan, Operability-Oriented Configurations of the Soft DecisionMaking Methods Proposed between 2013 and 2016 and Their Comparisons, Journal of New Theory (34) (2021) 82-114.

[46] S. Enginoğlu, S. Memiş, T. Öngel, Comment on Soft Set Theory and Uni-Int Decision Making [European Journal of Operational Research, (2010) 207, 848-855], Journal of New Results in Science 7(3) (2018) 28-43.

[47] S. Enginoğlu, S. Memiş, B. Arslan, Comment (2) on Soft Set Theory and uni-int Decision Making [European Journal of Operational Research, (2010) 207, 848-855], Journal of New Theory (25) (2018) 84-102.

[48] S. Enginoğlu, S. Memiş, N. Çağman, A Generalisation of Fuzzy Soft Max-Min Decision-Making Method and Its Application to A Performance-Based Value Assignment in Image Denoising, El-Cezerî Journal of Science and Engineering 6(3) (2019) 466-481.

[49] S. Enginoğlu, S. Memiş, F. Karaaslan, A New Approach to Group Decision-Making Method Based on TOPSIS under Fuzzy Soft Environment, Journal of New Results in Science 8(2) (2019) 42-52.

[50] S. Enginoğlu, T. Öngel, Configurations of Several Soft Decision-Making Methods to Operate in Fuzzy Parameterized Fuzzy Soft Matrices Space, Eskişehir Technical University Journal of Science and Technology Applied Sciences and Engineering 21(1) (2020) 58-71.

[51] S. Enginoğlu, S. Memiş, A New Approach to the Criteria-Weighted Fuzzy Soft Max-Min Decision-Making Method and Its Application to a Performance-Based Value Assignment Problem, Journal of New Results in Science 9(1) (2020) 19-36.

[52] S. Enginoğlu, T. Aydın, S. Memiş, B. Arslan, SDM Methods' Configurations (2017-2019) and Their Application to a Performance-Based Value Assignment Problem: A Follow up Study, Annals of Optimization Theory and Practice (In Press) 